\title{
ARTIGO
}

DOI: https://doi.org/10.22481/praxis.v15i31.4676

\section{QUALIDADE DO ENSINO E ESCOLA DE TEMPO INTEGRAL}

\author{
QUALITY OF TEACHING AND SCHOOL OF INTEGRAL TIME
}

CALIDAD DE LA ENSEÑANZA Y ESCUELA DE TEMPO INTEGRAL

\author{
Cristiane Machado \\ Universidade Estadual de Campinas - Brasil
}

\begin{abstract}
Resumo: Este artigo pretende explorar as concepções de qualidade do ensino que permeiam políticas e iniciativas de educação integral e escola de tempo integral por meio de artigos que debateram possíveis relações entre a ampliação do tempo de permanência na escola e incrementos na qualidade do ensino. Os textos selecionados compõem o mapeamento da produção sobre educação integral e escola em tempo integral em artigos de periódicos científicos que constam no Portal de Periódicos da Coordenação de Aperfeiçoamento de Pessoal de Nível Superior (Capes) no período de 2008 a 2017, elaborado por Machado e Ferreira (2018). Para este estudo foram selecionados, por meio do recurso 'localizar' do word, 18 (dezoito) artigos que analisaram a qualidade do ensino na perspectiva programática e da implementação de iniciativas de educação integral. Conclui que as concepções de qualidade nos textos explorados, em geral, se referem ao desempenho dos estudantes nas avaliações, tanto as padronizadas em larga escala como, também, nas aplicadas pelos professores em sala de aula. Finaliza indicando que a escola em tempo integral é uma possibilidade efetiva de melhorar a qualidade do ensino, contudo, indica que esforços precisam ser adotados para que outras dimensões da educação escolar sejam atendidas, como aspectos da qualidade do ensino, como organização política e pedagógica das atividades oferecidas, formação permanente dos profissionais que atuam em tempo integral, infraestrutura para as atividades complementares, para fortalecer e estimular todo o potencial desta política educacional em incrementar melhorias da qualidade do ensino.
\end{abstract}

Palavras-chave: Qualidade do ensino. Educação integral. Periódicos.

\begin{abstract}
This article intends to explore conceptions of quality of education that permeate policies and initiatives of integral educaction and full time school through articles that discussed possible relations between the extension of the time of permanence in the school and increases in the quality of the education. The selected texts compose the mapping of the production on integral education and full-time school in articles of scientific journals that appear in the Portal of Periodicals of the Coordination of Improvement of Personnel of Superior Level (Capes) in the period from 2008 to 2017, elaborated by Machado and Ferreira (2018). For this study, 18 (eighteen) articles were selected through the 'locate' feature of the word, which analyzed the quality of teaching in the programmatic perspective and the implementation of integral education initiatives. It concludes that the conceptions of quality in the texts explored, in general, refer to the performance of the students in the evaluations, both the standard ones in large scale as well as those applied by the teachers in the classroom. It concludes by indicating that full-time schooling is an effective possibility to improve the quality of
\end{abstract}


teaching, however, it indicates that efforts need to be adopted so that other dimensions of school education are addressed, as aspects of the quality of teaching, as a political and pedagogical organization of activities offered, permanent training of professionals who work full time, infrastructure for complementary activities, to strengthen and stimulate the full potential of this educational policy in increasing improvements in the quality of teaching.

Keywords: Quality of teaching. Integral education. Newspapers.

Resumen: Este artículo pretende explorar las concepciones de calidad de la enseñanza que permean políticas e iniciativas de educación integral y escuela de tiempo completo a través de artículos que debatieron posibles relaciones entre la ampliación del tiempo de permanencia en la escuela y los incrementos en la calidad de la enseñanza. Los textos seleccionados componen el mapeo de la producción sobre educación integral y escuela a tiempo completo en artículos de revistas científicas que constan en el Portal de Periódicos de la Coordinación de Perfeccionamiento de Personal de Nivel Superior en el período de 2008 a 2017, elaborado por Machado y Ferreira (2018). Para este estudio fueron seleccionados, a través del recurso 'localizar' del word, 18 (dieciocho) artículos que analizaron la calidad de la enseñanza en la perspectiva programática y de la implementación de iniciativas de educación integral. Concluye que las concepciones de calidad en los textos explotados, en general, se refieren al desempeño de los estudiantes en las evaluaciones, tanto las estandarizadas a gran escala como, también, en las aplicadas por los profesores en el aula. En el caso de la enseñanza a tiempo completo es una posibilidad efectiva de mejorar la calidad de la enseñanza, sin embargo, indica qué esfuerzos necesitan ser adoptados para que otras dimensiones de la educación escolar sean atendidas, como aspectos de la calidad de la enseñanza, como organización política y pedagógica las actividades ofrecidas, la formación permanente de los profesionales que actúan a tiempo completo, infraestructura para las actividades complementarias, para fortalecer y estimular todo el potencial de esta política educativa en incrementar las mejoras de la calidad de la enseñanza.

Palabras clave: Calidad de la enseñanza. Educación integral. Publicaciones periódicas.

\section{Introdução}

A preocupação com a qualidade da educação escolar, no Brasil, não é recente, entretanto é somente na contemporaneidade que ela adquire a configuração de ser referenciada no desempenho dos estudantes. Estudo de Oliveira e Araújo (2005) demarca três diferentes significados da noção de qualidade da educação brasileira. Em um primeiro momento o acesso era tido como referência de qualidade, tendo em vista os limites de oportunidades de escolarização, no segundo a preocupação girava em torno da permanência na escola, ou seja, relacionava-se ao alto movimento de reprovações de alunos nos sistemas de ensino e, por fim, o terceiro momento associa qualidade aos resultados alcançados pelos estudantes nas avaliações em larga escala.

A literatura salienta que o conceito qualidade é polissêmico (DOURADO, 2007; CURY, 2014), eivado de ambiguidade (RISOPATRON, 1991) e historicidade (SILVA, 
1996). Sousa (1997, p. 267) chama a atenção para o fato de que “qualidade não é 'algo dado', não existe 'em si', remetendo à questão axiológica, ou seja, dos valores de quem produz a análise de qualidade". Azevedo (1994, p. 456) assevera que "qualidade não é um atributo neutro, nem é desprovida das significações que lhe reservam os agentes que dela estão tratando, de acordo com seus interesses e valores específicos”. Nas palavras de Cury (2014, p. 1.054), "é um termo polissêmico e cuja definição não só carece de uniformidade como também se louva em sentidos de muita complexidade" sendo, portanto, necessário definir o que se entende por qualidade do ensino.

Assim, este artigo tem o objetivo de explorar as concepções de qualidade do ensino que permeiam as políticas de educação integral e as iniciativas de escola de tempo integral por meio de artigos que investigaram os sentidos de qualidade nas propostas governamentais e as relações entre a ampliação do tempo de permanência na escola e incrementos na qualidade do ensino nas inciativas implementadas. Os textos selecionados compõem o mapeamento ${ }^{1}$ da produção sobre educação integral e escola em tempo integral em artigos de periódicos científicos que constam no Portal de Periódicos da Coordenação de Aperfeiçoamento de Pessoal de Nível Superior (Capes) no período de 2008 a 2017, elaborado por Machado e Ferreira (2018).

A relevância desse estudo se apoia no reconhecimento de que a educação integral no Brasil, na perspectiva de ampliação do tempo de permanência na escola, tem se constituído, cada vez mais, como uma das respostas viáveis para potencializar a aprendizagem dos estudantes e, assim, melhorar a qualidade do ensino.

A primeira importante experiência de escola em tempo integral foi materializada, em 1952, por Anísio Teixeira com a construção do Centro Educacional Carneiro Ribeiro (CECR), espaço educacional com atividades intelectuais e práticas durante todo o dia, na cidade de Salvador (BA).

No início dos anos de 1980, Darcy Ribeiro idealizou os Centros Integrados de Educação Pública (CIEPs), experiência pautada nos princípios da educação integral em dois sentidos: educar o estudante em todas as suas dimensões e ampliar o tempo de permanência na escola para 8 horas diárias.

\footnotetext{
${ }^{1}$ Elaborado inicialmente, em 2017, por Telma Cristina do Nascimento em pesquisa de Iniciação Científica no âmbito do Programa Nacional de Cooperação Acadêmica - PROCAD, tendo como referência o período de 2008 a 2016 e complementado em 2018, com informações de 2017, por Larissa Barbosa Ferreira, Mestranda na Faculdade de Educação da Universidade Estadual de Campinas.
} 
No governo Collor, na década de 1990, foram criados os Centros Integrados de Atendimento à Criança (CIACs), posteriormente renomeados para Centro de Atenção Integral à Criança (CAICs) por Itamar Franco como após o impeachment de Collor. Foram construídas apenas 200 unidades em várias cidades, apesar da promessa de chegar a 5 mil equipamentos. O objetivo era ampliar o tempo de permanência dos estudantes na escola, oferecendo uma educação em tempo escolar integral.

Já nos anos 2000, em São Paulo, foram implantados os Centros Educacionais Unificados (CEUs), na gestão da prefeita Marta Suplicy, a partir de uma ideia originada no governo municipal de Luiza Erundina, em 1992. O projeto, ainda em funcionamento com cerca de 120 mil estudantes distribuídos em 46 CEUs, foi concebido como uma proposta intersetorial fundamentada no princípio de atuar, de forma articulada, em diversas áreas: meio ambiente, educação, emprego e renda, participação popular, desenvolvimento local, saúde, cultura, esporte e lazer.

Em 2007, por meio da Portaria Interministerial n ${ }^{\circ}$ 17/2007, o governo federal instituiu o Programa Mais Educação com o propósito de criar as condições para a ampliação da jornada escolar, prioritariamente, em escolas com baixo Ideb e localizadas em regiões de vulnerabilidade social. O inciso II do Art. $2^{\circ}$ explicita que o Programa tem o objetivo de “contribuir para a redução da evasão, da reprovação, da distorção idade/série, mediante a implementação de ações pedagógicas para melhoria de condições para o rendimento e o aproveitamento escolar" (BRASIL, 2007, p. 02), demonstrando clara intenção de influenciar na qualidade do ensino.

Dados divulgados pelo Instituto Nacional de Estudos e Pesquisas Anísio Teixeira INEP (BRASIL, 2017) demonstram que, de 2010 a 2015, o número de matrículas em tempo integral no ensino fundamental mais que triplicou, passando de 1.327.129 para 4.648.277 de estudantes, indicando tanto o reflexo da política empreendida pelo governo federal como a pertinência de estudos que se dedicam a conhecer e compreender a organização da escola em tempo integral no país e seu potencial em ampliar a qualidade do ensino oferecido.

\section{Qualidade do ensino e escola de tempo integral nos periódicos}

O mapeamento no qual este trabalho se ancora (MACHADO; FERREIRA, 2018) localizou 135 artigos publicados entre 2008 e 2017 em periódicos assentados no Portal de Periódicos da Capes. Para o levantamento dos textos que possuíam interface com o tema 
qualidade foi utilizado o recurso 'localizar' do word nos resumos, palavras-chave e texto completo dos 135 artigos. Foram encontrados 18 títulos. A leitura na íntegra de cada um evidenciou que 10 deles debateram teoricamente o tema qualidade nos programas propostos no país (CAVALIERE, 2010; SILVA; SILVA, 2013; SILVA; SILVA, 2014; MACHADO; FREITAS; LONDERO; AHMAD, 2014; LIMONTA，2014; PIO; CZERNISZ, 2015; SCHIMONEK, 2015; KLEBIS; PAIOLA; LIMA 2015; SCHMITZ; SOUZA， 2016; ZANARDI, 2016) e 8 analisaram a qualidade na perspectiva da implementação de iniciativas de educação integral e seu potencial em melhorar a qualidade do ensino (BORBA; DINALLI, 2009; ESQUINSANI, 2010; MACHADO, 2010; CASTRO; LOPES, 2011; COELHO, 2012; SOLA; TORALES, 2013; ANDRADE; WIEBUSCH; SEGAT, 2016; PARENTE, 2017) ${ }^{2}$. Para uma melhor organização didática da apresentação dos artigos, optou-se por seguir a separação e a ordem descritas anteriormente.

Cavaliere (2010) investigou a concepção de educação integral no pensamento de Anísio Teixeira, que passou por momentos diferentes e diversos ao longo de toda a sua obra, entretanto, o desenvolvimento de suas ideias sempre manteve como premissa a qualidade da educação popular, dentre outras. Anísio Teixeira esteve no epicentro do inflamado debate sobre a expansão de vagas e a manutenção da qualidade dos sistemas públicos, que teve início nos anos 1920, com a crescente pressão popular por acesso aos bancos escolares. Foi um crítico ferrenho de iniciativas governamentais pautadas na redução do tempo de permanência nas escolas como forma de abarcar um maior contingente de matrículas uma vez que, para ele, havia uma "profunda relação entre o prédio escolar e a qualidade do ensino na escola de horário integral" (CAVALIERE, 2010, p. 256). Segundo a autora, Anísio Teixeira asseverava que "ao lado dessa simplificação na quantidade, seguiram-se, como não podia deixar de ser, todas as demais simplificações de qualidade” (CAVALIERE, 2010, p. 257).

Analisar a concepção de educação integral do Programa Mais Educação por meio de documentos que o fundamentaram foi o objetivo do artigo de Silva e Silva (2013). Os autores constataram que o programa se assenta em uma concepção intercultural, baseada em uma gestão intersetorial e sistêmica, com instrumentos de democratização e inovação com potencial de melhorar a qualidade da educação. Sobre o conceito de qualidade explicam:

O Programa Mais Educação defende a elaboração de um quadro conceitual, no qual a pactuação da qualidade na educação considere o valor das diferenças. Assim, a proposta busca inspiração nos estudos culturais, com

\footnotetext{
${ }^{2}$ Os artigos, nos dois casos, estão citados por ordem crescente de ano de publicação.
} 
base em ideias de antropólogos e pensadores da cultura contemporânea. (SILVA; SILVA, 2013, p. 704).

Em artigo posterior, os mesmos autores, Silva e Silva (2014), retomam análises sobre a de educação integral do Programa Mais Educação e concluem que a perspectiva de gestão intersetorial adotada pelo programa pode se apresentar como possibilidade de trazer mais qualidade para a educação, tendo em vista permitir a superação de fronteiras, uma vez que no âmbito municipal, “esse novo princípio de gestão sugere que cada um poderá participar da definição de seus critérios de implementação, de acordo com a importância que se tem em cada realidade" (SILVA; SILVA, 2014, p. 101-102).

Machado, Freitas, Londero e Ahmad (2014) estudaram o funcionamento e a implantação do Programa Mais Educação em um município do Rio Grande do Sul com o objetivo de verificar as possibilidades de melhoria na qualidade do ensino. Para as autoras "é evidente a importância que o Programa Mais Educação, assim como diversos outros programas possuem na educação, pois eles auxiliam no desenvolvimento educacional e social dos alunos que participam do programa" (MACHADO; FREITAS; LONDERO; AHMAD, 2014, p. 90). Ressaltam, ainda, que iniciativas como essa trazem benefícios que vão além da aprendizagem, uma vez que resvalam no âmbito social da formação humana, pois inserir essas crianças integralmente na escola é criar condições para que elas participem de diversas oficinas, recebam alimentação e tenham acesso a um ensino com qualidade.

Limonta (2014) discute, com base em revisão e análise bibliográfica, o projeto nacional de escola de tempo integral articulando o debate em torno da história, política e reflexões teóricas acerca da organização curricular e do trabalho pedagógico em escolas de jornada ampliada e conclui:

A escola de tempo integral pode se constituir num verdadeiro movimento teórico, político e pedagógico capaz de ressignificar a função social da educação e da instituição escolar. É preciso aproveitar este momento histórico e transformar a escola pública. No entanto, só fará sentido pensar a escola de tempo integral se a concepção de educação integral que a sustenta representar uma ampliação das oportunidades e situações que promovam aprendizagens significativas e emancipadoras. A melhoria da qualidade da escola pública brasileira é uma necessidade radical que não pode mais ser adiada. (LIMONTA, 2014, p. 133).

O artigo de Pio e Czernisz (2015) investigou a proposta de educação integral no Programa Mais Educação no Governo Lula. Por meio de estudo bibliográfico e documental as autoras verificam que na primeira fase do governo a educação era apresentada como meta de 
inclusão social e, no segundo mandato, como meta do desenvolvimento do país a partir da educação de qualidade (PIO; CZERNISZ, 2015, p. 241). Sobre a educação no Governo Lula e, em especial, o Programa Mais Educação concluem que:

[...] o que fica patente no Governo Lula é uma proposta educacional que se diz preocupada com a qualidade educacional, com a formação crítica dos educandos, mas que, na verdade, as considera o motor do desenvolvimento econômico do país, buscando desenvolver programas educacionais para amenizar problemas sociais, como a vulnerabilidade social, a fome, o analfabetismo, a formação técnica, entre outros. (PIO; CZERNISZ, 2015, p. 250).

Analisar a qualidade do ensino e a privatização via o Programa Mais Educação é o objetivo de Schimonek (2015). Indaga a autora se "o programa, de fato, tem impacto positivo na melhoria da qualidade do ensino público" (SCHIMONEK, 2015, p. 511). Conclui que o “Programa Mais Educação não constitui uma proposta de educação integral de qualidade para todos; é uma política focalizada que se apoia numa perspectiva humanitária para justificar uma educação acolhedora para pobres" (SCHIMONEK, 2015, p. 514).

Debater os impasses e as perspectivas da educação integral relacionados ao direito à educação tanto no Programa Mais Educação como, também, no Cidadescola implementado na cidade de Presidente Prudente, por meio de pesquisa bibliográfica de abordagem qualitativa, é o propósito de Klebis, Paiola e Lima (2015). As autoras afirmam que "embora tenham ocorridos avanços, será preciso ainda vencer vários desafios para se atingir a qualidade desejada, para uma educação que propicie a emancipação social e humana dos alunos da escola pública" (KLEBIS; PAIOLA; LIMA, 2015, p. 106) e finalizam ressaltando que "os desafios ainda são muitos para que essa educação integral não seja apenas sinônimo de ampliação do tempo, mas aponte para a concretização de uma educação que tenha a qualidade necessária para que seja mais democrática e inclusiva” (KLEBIS; PAIOLA; LIMA, 2015, p. 121)

Schmitz e Souza (2016) investigaram os limites das atuais avaliações externas de larga escala para verificar a qualidade da escola em tempo integral com o objetivo de refletir sobre uma possível sistematização de critérios de qualidade para a escola em tempo integral, com vistas a avaliar a sua eficácia. Argumentam as autoras que após oito anos da proposição do Programa Mais Educação como indutor de políticas em tempo integral no Brasil e da multiplicação de propostas de escolas de tempo integral pelo país, urge analisar a eficácia da 
escola em tempo integral e os impactos da ampliação do tempo para a melhoria da qualidade da educação. Ao finalizar a reflexão proposta asseguram que:

Como desafios impostos a gestores de políticas educacionais, destacam-se um repensar da escola em termos meso, como os critérios anteriormente elencados apontaram, e a elaboração de mecanismos efetivos para o monitoramento e a avaliação da qualidade pretendida com a ampliação da jornada escolar. (SCHMITZ; SOUZA, 2016, p. 577).

Partindo da constatação de que a Escola em Tempo Integral tem sido considerada um importante meio para uma educação de qualidade, a intenção de Zanardi (2016) foi apresentar o potencial da teoria freireana para o desenvolvimento de uma escola em tempo integral estabelecida sobre o paradigma de uma educação integral que possibilite a articulação entre os saberes, de forma crítica e dialógica. Para o autor, “com fundamento em Freire, é possível um projeto educativo integrado, em sintonia com a vida, as necessidades, possibilidades e interesses dos educandos(as), como deseja a concepção de Educação Integral do MEC" (ZANARDI, 2016, p. 104).

Borba e Dinalli (2009) exploraram as representações sociais de gestores, docentes, discentes e pais sobre a Escola de Tempo Integral (ETI) e o direito ao ensino de qualidade. Concluíram que o direito ao ensino de qualidade é entendido como um fato real na escola de tempo integral, entretanto, o tempo de permanência do aluno na escola não é uma condição sine qua non para a garantia deste direito, tampouco para o sucesso escolar. O estudo evidenciou, ainda, que:

[...] para os pais o mais importante é a permanência da criança na escola, pois lá podem ter uma alimentação equilibrada e ficar distantes dos perigos que a rua oferece. Estas concepções contribuem para a discussão sobre o papel de toda a comunidade escolar na busca pela qualidade do ensino e na garantia de direitos educacionais inerentes ao cidadão. (BORBA; DINALLI, 2009, p. 169).

A pesquisa de Esquinsani (2010) se debruçou em refletir sobre o direito à educação com base nos preceitos de Norberto Bobbio e em informações obtidas em pesquisa empírica em escolas públicas organizadas em tempo integral. Foi realizado um monitoramento, durante quatro anos (2005-2008), das duas abordagens do estudo: análise de conteúdo de fontes documentais (jornais de circulação local, atas de reuniões e relatórios elaborados a partir de encontros de formação com professores e gestores) e revisão bibliográfica sobre o tema. De acordo com a autora, "foi possível constatar que a escola em tempo integral é, de fato, uma possibilidade concreta de qualidade na educação pública” (ESQUINSANI, 2010, p. 260), 
destaca, ainda, duas questões centrais que impulsionam a qualidade na escola de tempo integral: a possibilidade de enfrentamento dos problemas sociais em comunidades de alta vulnerabilidade e a ampliação do tempo de permanência na escola que fortalece a exposição em relações sistematizadas de ensino-aprendizagem.

Machado (2010) examinou o potencial que a implementação da proposta de escola de tempo integral na rede municipal de Pouso Alegre (MG), no ano de 2009, teve de melhorar a qualidade do ensino. O procedimento adotado para abordar o tema foi o cotejamento de informações obtidas em entrevistas com gestores e professores dos alunos com jornada ampliada e os índices de aprovação e reprovação das escolas. A autora afirma que há fortes indícios de que a ampliação da jornada escolar tem potencial de melhorar a qualidade do ensino, uma vez que os índices de reprovação arrefeceram nas escolas participantes do projeto no ano considerado.

Analisar a correlação entre os objetivos arrolados pela política educacional que implantou as escolas de tempo integral no ensino fundamental da rede pública estadual paulista, no ano de 2006, e os dados da experiência concreta com o objetivo de compreender os avanços, desafios e limites da proposição de uma educação pública de melhor qualidade foi o propósito de Castro e Lopes (2011). As autoras concluíram que a ampliação de tempo não pode ser o principal sentido da escola integral, mais sim a organização escolar com foco qualificado nas atividades obrigatórias e nas atividades de livre escolha do aluno (CASTRO; LOPES, 2011, p. 259). Destacam, ainda, que o projeto não se constituiu em diferencial para mudar e melhorar os índices de permanência e de aprendizagem do aluno na escola (CASTRO; LOPES, 2011, p. 270). Ao finalizar, chamam a atenção para o fato de que:

Apesar da hipótese inicial de que a permanência do educando na escola, com 9 horas de trabalho escolar, sob orientação de professores habilitados, seria um fator de melhoria da qualidade educacional e de queda nos índices de retenção, evasão etc, mesmo sabendo, de antemão, que o projeto Escola de Tempo Integral apresentava alguns problemas, conforme já pontuado, quanto mais avançávamos na pesquisa menos certeza tínhamos de que essa melhoria, decorrente da maior extensão do tempo de permanência discente na escola, realmente ocorreria. (CASTRO; LOPES, 2011, p. 277).

Coelho (2012) examinou a escola de tempo integral e seu potencial de produzir melhoria na qualidade do ensino com base em falas de alunos dos anos iniciais do ensino fundamental coletadas durante pesquisa nacional que trabalhou com experiências de ampliação da jornada escolar. A pesquisa demonstrou que os alunos percebem o potencial da escola integral implicar em melhoria na qualidade do ensino porque há um aumento na 
quantidade de atividades desenvolvidas e, consequentemente, alargamento do tempo de acompanhamento do trabalho pedagógico disponibilizado pelos professores (COELHO, 2012, p. 83)

Investigar as atividades de educação ambiental realizadas nas escolas de ensino integral da Rede Municipal de Ensino de Curitiba e relatar as atividades desenvolvidas dentro do espaço da escola de ensino integral foi o objetivo do artigo de Sola e Torales (2013). As autoras tiveram como pano de fundo o princípio de melhorar a qualidade do ensino exposto no Programa Mais Educação e concluíram:

Na perspectiva de alcançarmos essa qualidade, o Programa Mais Educação, vem sendo um meio que possibilita trabalhar com as mais variadas atividades que não estão presentes no currículo formal, mas, que são de extrema valia para o desenvolvimento dos alunos e o resgate dos valores morais e éticos. (SOLA; TORALES, 2013, p. 859).

A pesquisa de Andrade, Wiebusch e Segat (2016) investigou a educação em tempo integral na educação infantil de uma Escola Municipal da cidade de Santa Maria (RS) para compreender a proposta educativa realizada com as crianças que permanecem em tempo integral na escola. As autoras ressaltam a importância de aumentar as instituições para atender as crianças de zero a cinco anos e, assim, garantir uma melhor qualidade no atendimento às necessidades da população do município.

Infelizmente, vive-se a triste realidade de crianças que já estão matriculadas em uma escola de Educação Infantil e que, por falta de espaço físico adequado na instituição para que possam acolher a todas as crianças da comunidade escolar nas turmas de Turno Integral, perdem o direito de permanecer o tempo que necessitam por falta de vagas. Por serem de uma região de vulnerabilidade social, o direito a Educação Infantil gratuita, de qualidade, de tempo integral deveria ser prioridade para o poder público. (ANDRADE; WIEBUSCH; SEGAT, 2016, p. 585).

Parente (2017) examinou o Programa Mais Educação nas escolas do campo e apresentou reflexões sobre limites e possibilidades do programa e da educação em tempo integral. Os dados foram coletados por meio de questionários eletrônicos enviados às escolas públicas participantes do Programa Mais Educação. A pesquisa considerou diferentes dimensões da educação escolar, como: aumento na jornada escolar; registro de matrículas em tempo integral no Censo Escolar; condições relativas a recursos humanos, pedagógicos e financeiros; mudanças nos espaços físicos; oferta de atividades pedagógicas, culturais, artísticas e esportivas; melhoria nos canais de comunicação com a comunidade; viabilização de formação continuada; modificações no projeto político-pedagógico e no currículo escolar; 
alterações no comportamento dos alunos; melhoria no desempenho escolar; reforço na qualidade da alimentação escolar; criação e fortalecimento de parcerias; utilização de outros espaços físicos para atividades com estudantes (PARENTE, 2017, p. 439). Com base em análises quantitativa e qualitativa foram identificados importantes impactos do programa nas escolas do campo, especialmente, no que diz respeito à ampliação das oportunidades educativas. Entretanto, a autora ressalta que a pesquisa mostrou limites importantes do Programa Mais Educação originados, principalmente, pelas deficiências das contrapartidas dos entes federativos que inibem as possibilidades de impacto positivo do programa nas escolas (PARENTE, 2017, p. 453).

\section{Considerações finais}

O objetivo desse artigo foi explorar as concepções de qualidade do ensino que fundamentam as políticas de educação integral e referenciam as iniciativas de escola de tempo integral por meio de artigos que investigaram propostas e ações governamentais de ampliação do tempo de permanência na escola e o potencial de implicar em melhoria na qualidade do ensino.

Para tanto, foram selecionados 18 artigos, por meio do recurso 'localizar' do word nos resumos, palavras-chave e texto completo, de uma amostra de 135 publicados entre 2008 e 2017 em periódicos que integram o Portal de Periódicos da Capes e mapeados em pesquisa anterior por Machado e Ferreira (2018). A leitura na íntegra dos 18 artigos possibilitou perceber que 10 títulos debateram teoricamente o tema qualidade nos programas propostos no país e 8 analisaram a qualidade na perspectiva da implementação de iniciativas de educação integral e seu potencial em melhorar a qualidade do ensino.

A leitura dos artigos selecionados permite afirmar que a ampliação do tempo de permanência do estudante na escola é, de fato, uma possibilidade de melhoria na qualidade do ensino. Mas, que qualidade? Essa indagação faz sentido porque, como já afirmou Dourado (2007, p. 09), a qualidade na educação é "um fenômeno complexo, abrangente e que envolve múltiplas dimensões".

Observando as concepções de qualidade nos textos explorados nota-se que, em geral, o fundamento do conceito de qualidade do ensino abordado é aquele que se refere ao desempenho dos estudantes nas avaliações, tanto as padronizadas em larga escala como, também, as aplicadas pelos professores em sala de aula. 
Embora sejam extremamente relevantes os resultados obtidos, pelos estudantes, nas avaliações, é importante envidar esforços institucionais e políticos para que outras dimensões da educação escolar sejam atendidas como aspectos da qualidade do ensino, como organização política e pedagógica das atividades oferecidas, formação permanente dos profissionais que atuam em tempo integral, infraestrutura para as atividades complementares.

Alargar a concepção de qualidade do ensino ao propor políticas de educação integral e ao implementar iniciativas de ampliação do tempo de permanência na escola pode fortalecer e estimular todo o potencial que esta política educacional possui de incrementar a melhoria da qualidade do ensino.

\section{REFERÊNCIAS}

ANDRADE, Natália Desconsi de; WIEBUSCH, Andressa; SEGAT, Taciana Camera. Educação em tempo integral em uma escola de educação infantil de Santa Maria-RS: diálogos possíveis. RPGE- Revista on line de Política e Gestão Educacional, v.20, n.03, p. 579-599, 2016.

AZEVEDO, Janete. A temática da qualidade e a política educacional no Brasil. Educação \& Sociedade, Campinas, n. 49, especial, p. 449-467, dez. 1994.

BORBA, Valdinéa Rodrigues de Souza; DINALLI, A. O direito ao ensino de qualidade: representações sociais de uma comunidade. Nucleus, v.6, n.1, abr. 2009.

BRASIL. MEC. Portaria Normativa Interministerial $n^{\circ}$ - 17. Institui o Programa Mais Educação, que visa fomentar a educação integral de crianças, adolescentes e jovens, por meio do apoio a atividades sócio-educativas no contraturno escolar. Brasília, 24 de abril de 2007.

BRASIL. MEC. Instituto Nacional de Estudos e Pesquisas Anísio Teixeira - INEP. CENSO ESCOLAR 2016 - Notas Estatísticas. Brasília-DF. 2017.

CASTRO, Adriana de; LOPES, Roseli Esquerdo. A escola de tempo integral: desafios e possibilidades. Ensaio: aval. pol. públ. Educ., Rio de Janeiro, v. 19, n. 71, p. 259-282, abr./jun. 2011.

CAVAlIERE, Ana Maria. Anísio Teixeira e a educação integral. Paidéia, vol. 20, no. 46, maio-ago. 2010.

COELHO, Lígia Martha C. da C. Alunos no Ensino Fundamental, ampliação da jornada escolar e Educação Integral. Educar em Revista, Curitiba, Brasil, n. 45, p. 73-89, jul./set. 2012. 
CURY, Carlos Roberto Jamil. A qualidade da educação brasileira como direito. Educação \& Sociedade. Campinas. v.35, n. 129, p. 1053-1066, 2014.

DOURADO, Luiz Fernando. (Coord.). A qualidade da educação: conceitos e definições. Brasília: MEC/Inep, 2007.

ESQUINSANI, Serena Siqueira. A educação como um direito: o desafio da qualidade em uma experiência de escola pública. Roteiro, Joaçaba, v. 35, n. 2, p. 251-268, jul./dez. 2010.

KLEBIS, Augusta B. S. Oliveira; PAIOLA Osmarina Gomes; LIMA, Samara Correia. Educação integral: impasses e perspectivas dos Programas Mais Educação e CidadescolaPresidente Prudente. Colloquium Humanarum, Presidente Prudente, v. 12, n. 3, p.106-122, jul/set 2015.

LIMONTA, Sandra Valéria. Escola de Tempo Integral: Desafios Políticos, Curriculares e Pedagógicos. Educação: Teoria e Prática, Rio Claro, vol. 24, n.46, mai-ago. 2014.

MACHADO, Cristiane. Tempo integral na escola melhora a qualidade? RPGE- Revista on line de Política e Gestão Educacional, n.08, 2010.

MACHADO, Cristiane; FERREIRA, Larissa Barbosa. Educação Integral e Escola de Tempo Integral: mapeamento da produção científica em periódicos (2008 a 2017). Revista Exitus, Santarém/PA, vol. 8, n 3, p. 87-112, set/dez 2018.

MACHADO, Gabriella Eldereti; FREITAS, Flávia M. de; LONDERO, Janisse Vessozi; AHMAD, Laila Azize Souto. Estudo de uma política de educação básica tendo como enfoque a pesquisa sobre o Programa Mais Educação em uma escola da cidade de Alegrete. Regae: Rev. Gest. Aval. Educ. Santa Maria v. 3 n. 5 Jan./jun. 2014.

OLIVEIRA, Romualdo Portela de; ARAÚJO, Gilda Cardoso de. Qualidade do ensino: uma nova dimensão da luta pelo direito à educação. Revista Brasileira de Educação, Rio de Janeiro, v. 28, p. 5-23, Jan./Abr. 2005.

PARENTE, Cláudia da Mota Darós. Programa Mais Educação: impactos e perspectivas nas escolas do campo. Revista Eletrônica de Educação, v.11, n.2, p. 439-454, jun./ago., 2017.

PIO, Camila Aparecida; CZERNISZ Eliane Cleide da Silva. A educação integral no mais educação: uma análise do programa. Educação, Santa Maria, v. 40, n. 1, p. 241-254, jan./abr. 2015.

RISOPATRON, Veronica Edwards. El concepto de calidad de laeducación. Chile: Unesco/Orealc, 1991.

SCHIMONEK, Elisangela Maria Pereira. A qualidade do ensino público e a privatização via Programa Mais Educação. Educação: Teoria e Prática, Rio Claro, vol. 25, n.50, mai-ago. 2015. 
SCHMITZ, Heike; SOUZA, Maria Celeste Reis Fernandes de. Reflexões sobre possíveis critérios de qualidade da escola em tempo integral. Est. Aval. Educ., São Paulo, v. 27, n. 65, p. 552-581, maio/ago. 2016.

SILVA, Jamerson Antonio de Almeida da; SILVA, Katharine Ninive Pinto. A hegemonia às avessas no Programa Mais Educação. Rev. bras. Estud. pedagog., Brasília, v. 94, n. 238, p. 701-720, set./dez. 2013.

SILVA, Jamerson Antonio de Almeida da; SILVA, Katharine Ninive Pinto. Analisando a concepção de educação integral do governo Lula/Dilma através do programa mais educação. Educação em Revista, Belo Horizonte, v.30, n.01, mar. 2014

SILVA, Tomaz Tadeu. O projeto educacional da nova direita e a retórica da qualidade total. SILVA, Tomaz Tadeu; GENTILI, Pablo. Escola S. A.: quem ganha e quem perde no mercado educacional do neoliberalismo. Brasília: CNTE, 1996.

SOARES, José Francisco. Qualidade da educação: qualidade de escolas. VIANA, Fabiana Silva. et al. A qualidade da escola pública no Brasil. Belo Horizonte: Mazza, 2012. p. 7596.

SOLA, Elizabete Aparecida; TORALES, Marília Andrade. Programa mais educação: a educação ambiental na escola de tempo integral. Rev. Ibero-Americana de Estudos em Educação, Araraquara, SP, Brasil, vol. 8, n. 4, 2013.

SOUSA, Sandra Zákia Lian. Avaliação do rendimento escolar como instrumento de gestão educacional. In: OLIVEIRA, D. Gestão democrática da educação: desafios contemporâneos. Petrópolis, RJ: Vozes, 1997, p. 264-283.

ZANARDI, Teodoro Adriano Costa. Educação integral, tempo integral e Paulo Freire: os desafios da articulação conhecimento-tempo-território. Revista e-Curriculum, São Paulo, v.14, n.01, p. $82-107$ jan./mar.2016.

\section{$\underline{\text { SOBRE A AUTORA }}$}

\section{Cristiane Machado}

Doutora em Educação pela Universidade de São Paulo (USP). Docente do Programa de PósGraduação em Educação da Universidade Estadual de Campinas (Unicamp). Pesquisadora do Laboratório de Gestão Educacional (LAGE). E-mail: crimacha@unicamp.br 